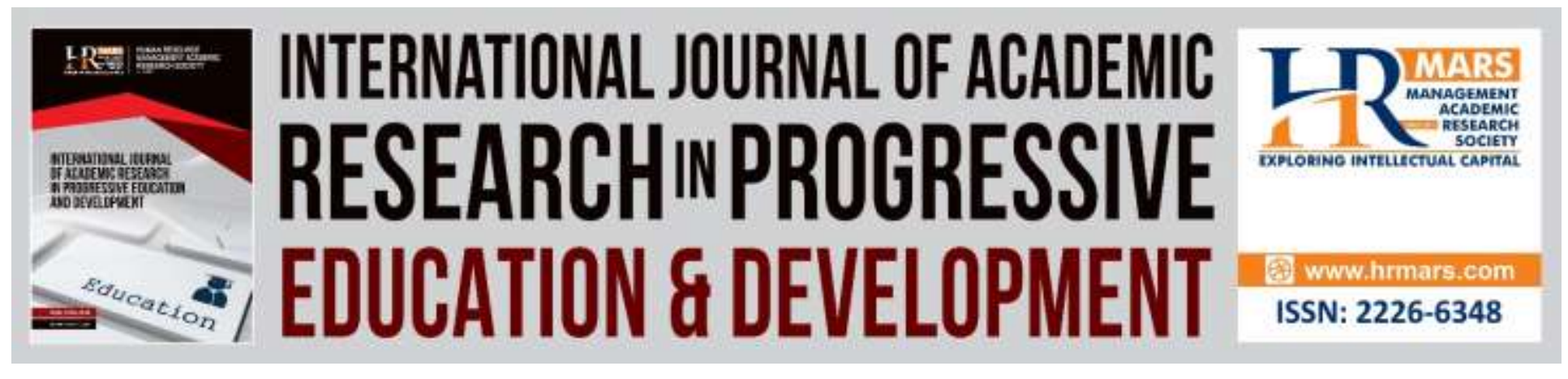

\title{
Exploring the Potential of Facebook Group Discussion Platform for Trainee Teachers' Reflective Practice
}

\author{
Natasha Ariffin, Abu Bakar Razali
}

To Link this Article: http://dx.doi.org/10.6007/IJARPED/v8-i4/6691

DOI:10.6007/IJARPED/v8-i4/6691

Received: 05 October 2019, Revised: 30 October 2019, Accepted: 10 November 2019

Published Online: 30 November 2019

In-Text Citation: (Ariffin, \& Razali, 2019)

To Cite this Article: Ariffin, N., \& Razali, A. B. (2019). Exploring the Potential of Facebook Group Discussion Platform for Trainee Teachers' Reflective Practice. International Journal of Academic Research in Progressive Education and Development, 8(4), 662-667.

Copyright: (C) 2019 The Author(s)

Published by Human Resource Management Academic Research Society (www.hrmars.com)

This article is published under the Creative Commons Attribution (CC BY 4.0) license. Anyone may reproduce, distribute, translate and create derivative works of this article (for both commercial and non-commercial purposes), subject to full attribution to the original publication and authors. The full terms of this license may be seen at: http://creativecommons.org/licences/by/4.0/legalcode

Vol. 8(4) 2019, Pg. 662 - 667

http://hrmars.com/index.php/pages/detail/IJARPED JOURNAL HOMEPAGE

Full Terms \& Conditions of access and use can be found at http://hrmars.com/index.php/pages/detail/publication-ethics 


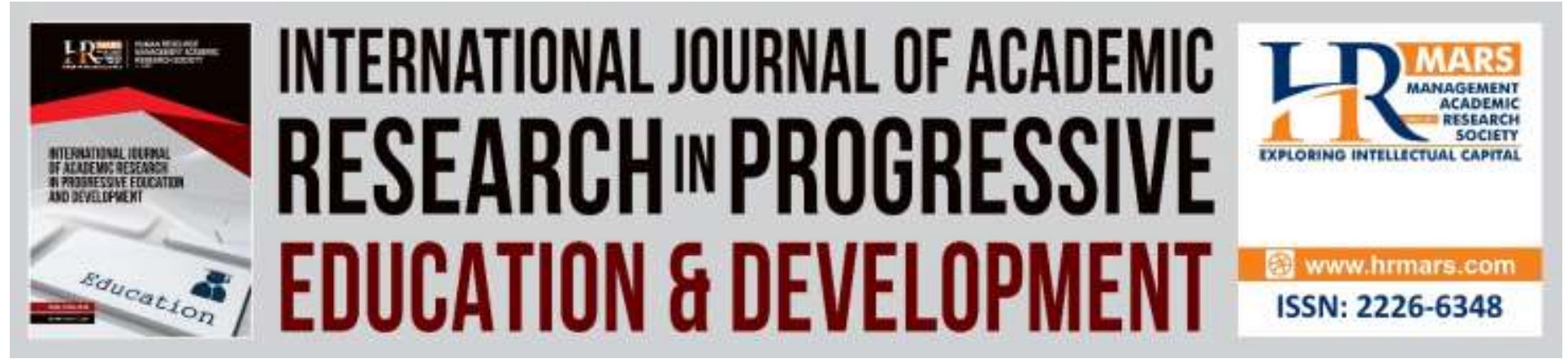

\title{
Exploring the Potential of Facebook Group Discussion Platform for Trainee Teachers' Reflective Practice
}

\author{
Natasha Ariffin \\ Faculty of Education, International Islamic University College Selangor, Selangor, Malaysia \\ Email: natasha@kuis.edu.my \\ Abu Bakar Razali \\ Faculty of Educational Studies, Universiti Putra Malaysia (UPM), Serdang, Selangor, Malaysia \\ Email: abmr_bakar@upm.edu.my
}

\begin{abstract}
The teacher training institution is an important place in supplying content and pedagogical training to teacher trainees. However, applying this knowledge in a natural setting is another challenge faced by the trainee teachers. Thus, there is a need to empower the capability of trainee teachers to refine their teaching skills independently. One of the ways to develop and cultivate this need is by improving how reflective practice is conducted during their teacher practice. The issue of improving the quality of reflective practice has been addressed especially through variety of mediums, such as the use of paper-based method and electronic-based method, and such as the use of blog sites, online forums and chat sites, and more recently social networking sites, like Facebook. However, the use of social networking websites, such as Facebook, have received little attention, even though a handful of studies have reported on its many benefits for reflective practice. Therefore, this conceptual paper is written to provide a review of past studies that explored the potential of using Facebook Group discussion platform for trainee teachers as a tool for reflective practice.
\end{abstract}

Keywords: Facebook, Social Networking Sites, Reflective Practice, Teacher Training, Trainee Teachers.

\section{Introduction}

Teacher training is a very important aspect in the development professionalism of teacher trainees. This is so that the teaching that will be conducted by these future teachers would be effective in developing the future generation. In the context of Malaysian education system, there are five basic principles of teacher training program based on Malaysian Qualifying Framework (MQF), which are outcome-based, coherent, spiral and developmental, holistic, as 
well as practical and contextual (Jamil, Razak, Raju, \& Mohamed, 2010). These basic principles are embedded in order to achieve specific learning outcomes in accordance with the 21st century skills. Due to that, assessment in the teaching training program must include the nature of basic and fundamental theoretical related to pedagogy knowledge and not forgotten in inserting and inculcating noble virtues in building a good characteristic of a teacher.

National Parent-Teacher Association chairman, Prof Datuk Dr Mohamad Ali Hasan, said the Malaysian candidate teachers must have good communication skills, interpersonal skills, soft skills, patience and stable emotional intelligence (Malay Mail Online, 17 March 2014). The teacher candidates should be versatile in terms of intelligence, emotional state and interpersonal skills. Since the teacher is the heart of education, fostering the best quality of trainee teachers during teacher education program is essential to ensure good quality teachers. As teachers, they are surrounded with challenges in dealing with students from multiple family background, socioeconomic, races and religious beliefs; just to name a few. It is essential for the future teacher to have the ability to adapt to changes especially in dealing with school communities. Thus, the capability to critically reflect through changes and challenges is essential and hopefully assisting future teachers to independently improve towards betterment.

Reflective practice was introduced since mid-1970s and still considered as a well-fledged practice in teacher education program. Reflective practice is commonly done during practicum session or also known as teaching practice where the trainee teachers get an insight of authentic teaching and learning experiences. Reflective practice is a common and vital practice in teacher education. According to Jones and Ryan (2014), a good teacher should have the capability to perform reflective practice. Facing challenges is a part of learning process which is something that should be embedded in trainee teachers' mind. Based on the recollection of memory of the challenges faced, the trainee teachers will examine the strengths and his/her weaknesses by writing reflections as a mode of documenting the problems or issues related. By gathering all the information, it allows the trainee teachers to analyses and implement actions on the outcomes of the lesson.

However, since trainee teachers are newly exposed to the teaching experience, the reflections written for the purpose of reflective practice still needed to be monitored and guided by the supervisors in order to facilitate the trainee teachers' progress in school. Kabilan (2008) mentioned that in improving the capability of trainee teachers learning and satisfaction with their learning, meticulous consultation with them can determine and cultivate higher self-confidence and efficacy (Oh et al., 2005). Trainee teachers are expected to gain and analyses a better understanding on the subject matter based on the feedback given by their supervisors and mentor teachers and prior knowledge that they have. Lee and Tan (2004) stated that reflective practice, such as the sharing of one's inner thoughts through journal writing or openly analyzing one's classroom teaching does require trainee teachers to take more responsibility for their own learning. Significantly, reflective practice is an on-going process of learning where the trainee teachers need to associate the link between theories learned and apply into practice in an authentic teaching and learning environment. Despite being independent learners, supervisors will provide commentary based on the decision or changes that the trainee teacher would like to implement to solve the issues or problems that occur. 
Despite equipping the trainee teachers well before practicum session, there is still question whether they are ready for practicum session. According to Yunus, Hashim, Ishak, and Mahamod (2010), trainee teachers showcased lack of readiness to go for teaching practicum even though they passed the requirement of subjects from the faculty. This is unavoidable since bridging between theories and practical is not an easy task especially when they are surrounded by the new environment in their teaching practicum experience. The problems and challenges that are faced by the trainee teachers occur in several aspects, which are on establishing new identities (Masry \& Saad, 2017) and pedagogy related area (Mutlu, 2014). A review of the pedagogical research literature that focuses specifically on this practicum aspect suggests that educators across the professions recognize the importance of enhancing this practical element (Carnegie, 2006; Clift \& Brady, 2005). The capability to be a reflective teacher is an essential skill for the trainee teacher not only to refine their teaching skill, but adapting to real working environment which might not be portrayed much during the teacher training program.

Bruster and Peterson (2013) stated that the emphasis on reflective practice challenges teacher educators to create programs that provide constructive ways for teacher candidates to engage in reflective practice. Other than that, reflective practice is one of the practices that have been emphasized in teacher education program which allows its practitioners to think critically of any particular actions in order for improvement towards any problems. By training the trainee teachers to be more independent learners, it can help them in order to make better decisions during real-life working experience. By observing, analyzing, and deciding on improving their own teaching practices, reflective practice can improve teacher performance, thus hopefully gives positive effects to the quality of teaching and learning process.

Coulson, Coulson, and Harvey (2013) state that reflective practice is widely discussed in the literature as a tool for promoting learning and higher order thinking skills; developing professional practice; and facilitating and structuring learning through experience. Reflective practice can be done based on daily lessons conducted by the teacher which mainly focuses on teaching and learning processes in the classroom. It is also can be done weekly where trainee trainees choose one issue, event or problem that might affect his/her concerns which revolve in the teaching and learning process in the classroom, dealing with school management or simply coping with inner thoughts of facing practicum session itself. From the medium of paper-based platforms, such as using diaries and traditional portfolios; nowadays, there are electronic-based platforms, like e-portfolio and blogging which are used to promote reflective practice among trainee teachers. Both reflective tools have their strengths and limitations. In Malaysia, each teacher education institution that provides teacher training programs have different tools for reflective practice, but majority of these institutions still opt for paper-based approach, such as the teaching portfolio.

As quoted in Ayan and Seferoglu (2011), writing teaching portfolios shift the responsibility and ownership of learning to the learner and encourage students to reflect on their own learning. In other words, the medium of paper-based cultivated originality and the sense of belonging to the trainee teachers. In addition, Cimer (2011) has conducted a research which focused on trainee teachers' view of using teaching portfolio as a medium of reflective practice. The findings show that by using paper-based medium of reflective practice, promoting learning and positive attitudes in one's learning could be achieved. Most of all, the capability of improving reflective 
and self-regulation skills among the trainee teachers can be achieved with continuous and immediate feedback.

Interestingly, over the last decades, the usage of Web 2.0 technologies for reflective practice has increased massively with the emergence of electronic-based tools. Reflective practice in electronic-based tools bring the same effect as paper-based; but through the capability of the communities to be online, idea collaboration and the sense of interactivity which make sharing and exchanging opinions through written dialogues at ease. Killeavy and Moloney (2010) described online communities of practice as professionals engaged in the social production of meaning. As exchanging immediate information and feedback can be achieved by electronic-based tools, there is a possibility to strengthen the quality of reflective practice in order to empower trainee teachers during teaching practice which cannot be accomplished if the medium of reflective tool is paper-based. As exchanging immediate information and feedback can be achieved by electronic-based tools, there is a possibility to equip the strength the quality of reflective practice in order to empower trainee teachers during teaching practice which cannot be accomplished if the medium of reflective tool is paper-based.

The rapid emergence of the Internet opens up the endless possibilities of knowledge accessing and multiple purposes especially in Malaysia. According to Department of Statistics Malaysia (2016), internet users in Malaysia were utilizing internet in a number of activities, such as social networking sites (84.3\%); getting information about goods and services (79.6\%); downloading images, movies, videos or music; playing or downloading games (76.1\%); and sending or receiving e-mails (68.4\%). Social networking sites, or also known as SNS, such as Facebook, Twitter, Instagram, Google+ and many more, are hugely dominating the usage of internet especially in Malaysia. Social networking radically changes and elevates the manners of keeping in touch, getting to know people, learning and getting new knowledge. The involvement of social media has definitely changed and transformed the way people communicate and so does the learning process.

According to Presky (2001) which had been advocated by Donlan (2012), the new generation of students have been termed 'digital natives' having grown up with an array of new technologies, and as such they expect to use multiple information media. Based on the Department of Statistics Malaysia, in 2015, percentage of individuals in Malaysia aged 15 years and above using Internet was $71.1 \%$ increased by $14.1 \%$ points compared with 2013 . It can be concluded that majority of students in Malaysia carried the highest percentage of internet users in Malaysia and the number has increasing since 2013. From this percentage it can be said that internet plays an important role among youth in this country.

Due to the nature of its features that cultivate content sharing, active interactions and participation, collaboration and critical thinking, researchers and educationists identify the potential and possibilities of utilizing SNS in learning environment. According to Malaysian Communication and Multimedia Commission (2018), 97.3\% of Malaysian has Facebook accounts in which allocate Malaysia to be among top 18 countries that are actively using Facebook. According to Wang, Woo, Quek, Yang, \& Liu (2012) Facebook Group possess quality as a learning management system which enables learning change from passive to active learning. Concurrently, dealing with trainee teachers who majority grew up with technology, there is a need to change the medium of communication and sharing knowledge and information. As being 
Vol. 8, No. 4, 2019, E-ISSN: 2226-6348 @ 2019 HRMARS

the most influential SNS in Malaysia, Facebook should be considered as a medium of reflective practice due to the interactive features that might help in promoting reflective practice among trainee teachers.

Facebook was not initially designed for educational purposes, but its unique characteristics, such as grouping around specific areas of interest, knowledge sharing, group discussions, and self-expression, brought it to the attention of educators as a potential learning environment (Kurtz, 2014). This is what makes Facebook different from other social networking sites. This feature allows the trainee teachers and the supervisors to be in the online community virtually even though they are separated by distance. Through online reflective practice in Facebook Group, trainee teachers can get connected with their supervisor, and vice versa, as the supervisors can also know the progress of the trainee teachers in school not only relying on the observation visit thus the problems that the trainee teachers face in school is not obsolete and repetitive.

\section{Reflective Practice and the Potential of Facebook}

Reflective practice is not a simple process and represented a major paradigm shift especially for the trainee teachers. Reflection enables trainee teacher to construct knowledge through asking questions, critiquing, evaluating, and helping them bridge the gap between imagined views and the realities of teaching (Lee, 2008). This practice allows the trainee teachers to not only refine their teaching skills, but it also enables them to be independent learners and at the same time utilise the theories they learn into practice. However, it appears that trainee teachers do not know how to reflect analytically or critically (Bruster \& Peterson, 2013). According to Killeavy and Moloney, (2010) teachers find it difficult to reflect on their own practice (Ball \& Cohen, 1999; Little, 1990). It is important to note; it is unreasonable to expect the trainee teachers to understand the nature and the importance of reflective practice without it being taught to them. Also, reflective practice must be conducted with an awareness and consciousness of the certain situation with a view of improvement. Thus, trainee teachers should be assisted in understanding the nature of reflective practice.

Accordingly, reflective practice is difficult for trainee teachers due to the nature of reflective practice that emphasizes on the engagement of critically and emotionally capabilities to examine one's ability. Zembylas (2004) illustrates that emotion is constructed and rooted within cultures. In Southeast Asian culture, Malaysian teachers face the challenge to open up their feeling and to reveal their vulnerabilities and weaknesses to be known by other individuals. Based on the research conducted by Mansor (2011) on reflective learning, the idea of sharing their thoughts in journal writing is an alien experience for them. Shyness and fear to open up will hinder trainee teachers to become a reflective teacher.

There is also a challenge of time given during practicum session which is known to be too short to allow the trainee teachers to develop the capability to be reflective. Sharar (2012) pointed out that the shortage of time contributes to improper understanding and attitude of reflective practice as they were repeating the same practices without making an effort for improvement. However, there are advocates who believed reflective practice can be taught and trained. Stuart and Weber (2013) stated that with explicit instruction the capability to be reflective can be taught to trainee teachers over the course of the semester. The involvement of 
supervisor in guiding and giving feedback to the trainee teachers is essential to ensure the relevance of reflective practice is implemented and explored.

Lee and Tan (2004) advocated that reflection has to be nurtured rather than allowed to just happen and this process demands supervisors' attention. The role of supervisor in reflective practice is to ensure the trainee teachers are on the right track by giving guidance and feedback. Written or verbal feedback that is given by the supervisor is solely to facilitate trainee teachers' understanding and decision-making. Subsequently, this activity is for the trainee teachers to have an insight of his/her performance and explore the possibilities of improvement during practicum session. Schon (1987) proposed that reflective practice involves the thoughtful consideration of one's own experiences in applying knowledge to practice while being coached by professionals in the discipline. Thus, there is a great importance for trainee teachers to be advised and monitored by supervisor in connecting the theory to practice during practicum session.

However, the problem regarding the supervisors guiding trainee teachers through reflective practice is that these supervisors lack time to monitor trainee teachers' performance in giving feedback every week, since monthly meeting is conducted only for two hours when verbal feedback is given to the student teachers. The issue was raised by Jones and Ryan, (2014) where the difficulties arise in achieving effective reflective discussion during practicum periods because trainee teachers are based off-campus for extended periods of time, a situation often exacerbated for trainee teachers who are placed in rural and regional schools because of significant distances from the home university, high travel costs, and the absence of other trainee teachers at the school. In relating to the problem with the context of the research, indeed the process of consultation is time consuming where during the visit at the trainee teachers' school, the supervisor needs to give feedback for the lesson that had been conducted on that day. Other than that, the supervisor is required to review and read the teaching portfolio to get an overview of trainee teachers' progress in terms of checking the observation review from the in-house teacher, school activities participated and also school projects conducted. To focus on reflective practice, reflections written are up to three or four reflections in total. This defeats the purpose of the supervisor to guide and yet to promote the importance of reflective practice to trainee teachers. More studies had raised doubts about the lecturers' understanding and commitment to reflective practice (Mohd Kamal, 1996; Salhah et al., 1997; Ratnavadivel, 1999).

It is important to note that the role of supervisor is to monitor the performance of trainee teachers during the practicum session, even though teaching practice emphasises on the role of trainee teachers to be independent, guidance; and that supervisors' feedback can cultivate trainee teachers towards improvement and confirm the certainty of techniques used. As quoted by Szabo and Schwartz (2011), teacher modelling, monitoring, and assessment of reflective practice were found successfully raise the level of critical thinking of discussions in the online space. The supervisor must give these feedback and acts as an expert to reconfirm the progress of trainee teachers during practicum session. By sharing weekly reflection written right after the end of each week, guidance and supervision is on continuous manner, not mainly during the evaluation visits only. Thus, trainee teachers would have more possibilities to improve their teaching practice.

The role of supervisor in reflective practice is to ensure the trainee teachers are on the right track by giving guidance and feedback. Written or verbal feedback that is given by the 
supervisor is solely to facilitate trainee teachers' understanding and decision-making. However, the problem regarding the involvement of the supervisors in guiding trainee teachers through reflective practice is to monitor trainee teachers' performance by giving feedback every week since monthly meeting is conducted only for two hours where verbal feedback is given to the trainee teachers. By using Facebook group, the supervisor and trainee teachers can connect, communicate and exchange opinions through this platform and instantly guides and addresses the problems or concerns face by the trainee teachers without delaying the obsolete concerns.

The development of reflective tool does revolve around communication especially in improving the sense of interactivity which is lacking in the traditional approach. As quoted by Kori, Pedaste, Leijen, \& Maeots (2014), regulative skills and capability to reflect can be enhanced by technology-enhanced learning environments with the help of supervisors, learning support and technological sources. Based on the problems mentioned above, there is a need to develop an online support system to ease the supervisor to monitor trainee teachers' progress through composing reflections. As mentioned earlier in the previous section, the rapid emergence of Web 2.0 and SNS technologies are something that cannot be stopped. As quoted from Bicen \& Cavus (2011), educators are now turning to Web 2.0 tools, drawing upon their ability to assist in creating, collaborating on and sharing content. Due to that, the usage of social networking sites is increasing especially in education.

Based on the literature, an online reflective tool can be an important medium to solve the challenges in promoting reflective practice among trainee teachers. Being viewed as the most popular SNS in Malaysia, Facebook group discussion platform is seen as viable option to promote reflective practice due to its interactivity and capability of serving as a platform to monitor reflective practice. As quoted by Kumar, Joshi, and Sharma (2016), the exceptional user-friendly features of Facebook such as discussion on course topics, feedback from peers and group collaboration entitled this SNS to serve educational purposes. Based on these features mentioned, the authors see the potential of Facebook in promoting reflective practice among trainee teachers in two main aspects which are the capability to serve digital natives and provide mutual online support system.

Having Facebook as a reflective tool creates an online community support group where trainee teachers are allowed to share their teaching experiences through weekly reflections written. Reflective practice can be elevated through ideas collaboration and social interaction. It is important to note that in the Malaysian teacher education setting, majority of the trainee teachers are separated from one another during practicum session. As a result of this scenario, there is lack of meaningful mediums for the trainee teachers to discuss and collaborate in order to assist each other towards digesting ideas and inspiration. By engaging a community of trainee teachers in an online group discussion, sharing ideas, interaction, collaboration, active participation, information and resource sharing, and critical thinking can be cultivated (Sánchez, Cortijo, \& Javed, 2014).

As defined by Prensky (2001), digital natives are defined as those who are born in or after 1980 s or the members of Net Generations. This generation is said to be an expert of applying and adapting technology in an array of essentiality in their life due to its convenient. Due to that, there is a reason to adapt new teaching and monitoring approach to elevate their potentials especially in promoting reflective practice. Even though Facebook is seen as a social technology 
Vol. 8, No. 4, 2019, E-ISSN: $2226-6348$ @ 2019 HRMARS

tool rather than a formal teaching tool, it can improve trainee teachers' reflective practice which brings impact on academic performance especially in leading to higher level of self-esteem and social acceptance (Sánchez et al., 2014) and more importantly to prepare them to be teachers in the actual teaching profession.

\section{Review of Past Research on the Use of Facebook as a Reflective Practice Tool}

Facebook is one of the most developed and popular social networking sites in the world, and even in Malaysia. Carr and Hayes (2015) defined social media as "Internet-based, disentranced, and persistent channels of mass personal communication facilitating perceptions of interactions among users, deriving value primarily from user-generated content. Facebook is regarded as a pioneer of a new era of sophisticated technology of communication. In the third quarter of 2012, the number of active users had surpassed 1 billion making it the first social networking site ever to do so. The existence of Facebook changes the way we communicate, socialize and establish the trend virtually.

Facebook can be accessed from a large range of devices such as desktop computers, laptops, tablet computers and smartphones with internet connectivity. In February 2012, Facebook had over 845 million users (more than the population of Europe) who spent more than 9.7 billion minutes per day on the site (Facebook, 2012; Rusli, 2012). In the third quarter of 2018, Facebook now has 2.27 billion monthly users. According to Malaysian Digital Landscape 2016, Facebook was ranked as the first social networking site in Malaysia. User's share four billion pieces of content per day, including uploads of 250 million photos, and Facebook is now integrated with over seven million websites and applications (Facebook, 2012; Tsotsis, 2011).

Wilson, Gosling, and Graham, (2012) discuss why people use Facebook to which they believe that the sense of interactivity of Facebook is definitely enormous and limitless where people can share information, announcement, memories and knowledge by using Facebook. Allowing the users to continuously stay in touch with friends, relatives and other acquaintances wherever they are in the world, as long as there is access to the Internet is one of features in Facebook. Majority of Facebook users are utilizing this social networking sites due to its social engagement. The activities that are involved users' desire to keep in touch with friends (Ellison, Steinfield, \& Lampe, 2006; Joinson, 2008; Lampe, Ellison, \& Steinfield, 2006; Saleh, Jani, Marzouqi, Khajeh, \& Rajan, 2011; Sheldon, 2008). Other than that, it can also unite people with common interests or beliefs through groups and other pages because of the widespread reach of its network.

Facebook tends to encourage its users to engage in Facebook-related behaviors, such as the features on the site like the birthday reminder or automatic e-mails sent by Facebook to users (Viswanath, Mislove, Cha, \& Gummadi, 2009). Other than that, Facebook may help maintain previous relationships even though the logistic is an issue. Not only are that, promoting physical grooming (gossip and small talks) and group stability possible by using Facebook. Wilson et al. (2012) added the motives for engaging in specific behaviors, such as adding content or joining groups. Due to these communicative and social functions, Facebook is often seen has its possibility as to be transformed in teaching and learning practices as it is more social, open and collaboration oriented. In the subtopics, the usage of social networking sites and Facebook in educational setting will be discussed further. 
Vol. 8, No. 4, 2019, E-ISSN: 2226-6348 @ 2019 HRMARS

In the early studies related to social networking sites, this medium was not seen as having the ability to be utilized in an educational setting even though the number of social media users do not seem to decline but much more prosperous each day. Madge et al. (2009) mentioned that students mainly use Facebook mainly for socializing especially in settling in the early years of their university life. However, students do not view Facebook to serve the purpose of their academic even though the features of Facebook such as information-sharing and learning community group can be seen serving the students for academically. Selwyn (2009) stated that social networking application like Facebook appears to provide a medium for communication where they simply chit chatting about anything related to university work. However, their conversation is merely informal communication.

Hussain (2012) had conducted a qualitative study among 600 4th semester trainee teachers of Faculty of Education of the Islamia University of Bahawalpur, Pakistan. Based on this study, the trend, reasons and problems of how social media was used were discovered further. The study revealed that majority (90\%) of the students prepared to use Facebook in an educational setting. The research discovered social media was used to promote collaboration in exchanging academic activities and developing social networks throughout the world. The problem that might hamper them in utilizing social media was regarding poor bandwidth of internet and electricity break down/ load shedding.

According to the research conducted by Donlan (2012) in exploring the views of students on the use of Facebook in educational context, $60 \%$ of the students liked the Facebook pages. Students' perspective towards Facebook is still as a social tool and to use it in an educational context distracted the focus. None of the students commented or shared and information. Based on the research, students favor the usage of it as getting updates about classes or viewing assignment support post question to the lecturers. However, collaborating ideas is seen as absurd since there is no mutual interest felt. In sharing information, students felt a sense of ownership for the knowledge that they gained which resulted lack of sharing. It can conclude that sense of collaborative learning is very lacking in this research.

Sendurur, Sendurur, and Yilmaz (2015) had conducted a research to find the effect of social media on their achievement and performance whether social media is considered as a threat to their academic achievement. Thus, a survey was conducted among 412 Information Technology trainee teachers. Results demonstrated that $62.7 \%$ of them use their devices a few times a day and Facebook is the most popular social networking sites among Google+, Twitter and Linkedln. It is also found that students are comfortable with social media when it is used as a communication tool among students and instructors.

However, this is a different scenario based on the study that was conducted by Manca and Ranieri (2016) which discovered that academic staff were not ready to incorporate social media in as a teaching tool be it for blended learning. They prefer social media was used towards personal sharing and connecting with peers in professional networks. This finding is supported by Hew (2011) that Facebook has very little educational use because it is mainly to keep in touch with known individuals and using it for other purpose might attract potential risk on privacy between the academic staff and students. This was agreeable by Grosseck, Bran, and Tiru (2011) found that the majority of students spend significant time on Facebook more for social uses and 
less for academic purposes, even if they take part in discussions about their assignments, lectures, study notes or share information about research resources.

Even so, Bosch (2009) stated that there are potential positive benefits of using Facebook in teaching and learning, particularly for the development of educational micro-communities. The participants of the research did face certain challenges, including ICT literacy, such as bandwidth limitations and predominance of English being a disadvantage. According to a qualitative research that was conducted by Prescott et al., (2015), seven academic members of staff at one UK University who currently use Facebook Group in their teaching were interviewed aged between 30 and 55. They believed Facebook is a good site to communicate with students as all their students used Facebook in an easy and quick manner. Lecturers felt class engagement had increased, and that all can share information and course related resources.

This supports previous research by Bosch (2009) where he found that Facebook was also viewed as beneficial in that it increased and enhanced the student experience through class discussions outside of the classroom. However, participants were aware of the importance for both lecturer (staff) and student to be conscious of their digital ethics and professionalism standard. Pimmer and Linxen (2012) had conducted a case study on the appropriation of Facebook as a medium of learning tool which illustrated and highlighted the possibility of using it. Participants of the research were seen an active user and capable to create engagement and interest towards the learning process. However, there was a question whether Facebook has the capability to not only establish interactive space but allowing in-depths discussion.

Villiers (2010) conducted a research on utilizing Facebook Group mainly for social purposes but the discussion facilities showcased the possibility to focus on academic use. Villiers (2010) found that this feature can help to monitor distance-learning in order to serve the purpose of discussion on academic or content-related topic. The quality of assignment completed was generally acceptable but the initial enthusiasm to complete and communicate rapidly and shared beyond study findings were remarkable. There is no issue of isolation even though it was a distance learning due to online virtual meet up. Several members did choose to maintain their privacy by maintaining anonymity.

Having a Facebook Group, allowed the all the fellow students to build on online community learning. This next paper explores social media use for learning in universities, through a study of the use of Facebook Groups by undergraduate students which discovered on, what motivates students to use Facebook Groups and what benefits they receive from doing so. Ahern, Feller, and Nagle (2016) found that the technological attributes of Facebook Groups lead to enhancing students 'motivation and enable them to achieve their goals. The technological attributes that were highlighted were; easy access and content control and meaningful communication mode.

Kurtz (2014) further points out students reported being engaged in interaction and active participation in the Facebook group and appreciated its major contribution to their own personal learning experience. In this next study, which is a comparative study where two virtual platforms of learning were utilized; Facebook Group and a course website. It is to find out whether these two platforms affect students' perceptions on learning and participation. Most of them embraced a Facebook group for their future academic courses, without giving up on a course website as the main source of course materials. She added further that Facebook group was 
perceived as a protected environment that fosters social learning processes while emphasizing learner involvement, active contribution, and frequent interaction with peers and instructor. The course website, on the other hand, was perceived as a learning content repository designed for traditional, individual learning processes, such as recalling and understanding the course content.

The second study which was conducted by Petrovic et al. (2016) compared Facebook Group and other online course program, i.e., Moodle. Moodle is a software package which commonly used for making online academic courses that is meant for distance learning or virtual learning (Desnica, Letic, \& Navalusic 2010; Kudumovic et al., 2010). Based on this qualitative research, the results showed a statistically significant difference in favour of Facebook based on these reasons; the ease of use, rapid in spreading information, good possibilities for data search, good Graphical User Interface (GUI) and lastly the stability of the system. On the contrary, Moodle was not in favour due to the distraction from learning even though it has good learning environment and safety and privacy of personal data.

The issue of privacy and safety of the data is further emphasized in the research conducted by Wang et al. (2012). This study confirms that privacy and Internet safety become a critical concern in social learning environments (Wishart, 2004), and students must feel safe, secure and comfortable when they are using socially enabled environments (Karahasanovic et al., 2009). Moreover, it did not support other format files to be uploaded directly such as PDF and PPT. Other than that, students were satisfied of the usage of Facebook Group as a learning management system as it can be used in putting up announcements, sharing resources, organizing weekly tutorials and conducting online discussions. Tananuraksakul (2015) reported in the respective research that Facebook Group can enhance language learning which lead to positive attitude and motivation. Based on the qualitative outcomes from 10 participants revealed that the relevancy, familiarity, the convenience of the function, features and interface of Facebook Group did give positive impacts.

Rasiah (2014) highlighted the effectiveness of social media to enhance teaching and learning in a team-based learning. He students' learning experience and motivation was assessed through content analysis of their reflective portfolios and their Facebook postings. The results clearly showed the positive impact that team-based strategy had on the students' learning experience and motivation. Facebook enriched students' educational experiences, increasing the relevance of the subject matter and encouraging students to collaborate effectively with their peers and faculty. Annamalai and Jaganathan (2017) had established Facebook Group to facilitate writing activity in order to improve students' narrative essay. This qualitative case study involved six students and a teacher from an urban school in the northern region of Malaysia. In this study, the trainee teacher needs to write a narrative essay individually via teacher's Facebook page. After that, they need to write feedback on the essay which the aspect of grammar, sentence structure, organization and content. The students were able give feedback on to micro aspects (grammar and sentence structures) but not macro aspects (macro aspects). Facebook was able to provide the medium of learning, but the capability not to comment further on the narrative essay was much more related to the ability of the students. 
Vol. 8, No. 4, 2019, E-ISSN: 2226-6348 @ 2019 HRMARS

\section{Discussion and Conclusion}

This review has clearly shown that there is high interest from scholars, teachers and preservice as well as in-service teachers in using social media in an academic setting. It could not be denied the sense of interactivity and information sharing in Facebook captivates and motivates trainee teachers to do better during their practicum session thus create a competitive but yet healthy learning environment. Equally important, having Facebook Group in an educational setting, in this case it serves trainee teachers who were undergoing practicum session, create solidarity medium among all the users. It provides virtual support for the trainee teachers to go through teaching practicum each day.

Other than that, features in Facebook do provide a systematic and structured organization of notifications. Moreover, the awareness of the features in Facebook in order to be responsive towards certain posts is clearly known by the trainee teachers even though it However, there is a sign of reluctance in responding further even though the features allowed them to express themselves in varied way. Contrarily, trainee teachers chose to respond in minimal manners ('like' the posts) rather than giving their opinions of improvement to their friends. They mentioned how reluctant they were to give feedback and criticism due to their questionable credibility. The function of the lecturer is still prominent in giving feedback and guidance if there is a possibility of the trainee teachers to improve her performance.

From the literature, it is found that Facebook Group can create a supportive medium in educational setting. Based on the research, trainee teachers were inspired by each other posts. They tend to replicate the ideas of each other in using the features of Facebook in elevating the reflection content to be more illustrative and interesting. Other than that, it can provide a source of information, ideas and inspiration among the trainee teachers during practicum session. Through the use of Facebook group discussion, supervisors and trainee teachers can share posts related to teaching ideas, tips and inspirational quotes related to teaching profession. This is shared as to introduce and provide the source of information that the trainee teacher can explore further indecently.

Therefore, more research should be conducted and explored to gather better understanding this subject matter in diverse perspectives. As an initial recommendation, there are recommendations stated below. Based on the responses from the trainee teacher, they are much more motivated to use Instagram rather than using Facebook. Thus, Instagram is more popular and appealing for them to utilized further. Due to that, in the future, perhaps Instagram can be investigated further to know the effectiveness of this social media in serving academic purpose since it triggers interest among the youngsters.

\section{Acknowledgement}

This research was made possible due to research grant in the scheme of Geran Putra (or Putra Grant) by Research Management Centre, Universiti Putra Malaysia (UPM).

\section{Corresponding Author}

Abu Bakar Razali (PhD), Faculty of Educational Studies, Universiti Putra Malaysia (UPM), Serdang, Selangor, Malaysia. Email: abmr_bakar@upm.edu.my 
INTERNATIONAL JOURNAL OF ACADEMIC RESEARCH IN PROGRESSIVE EDUCATION AND

DEVELOPMENT

Vol. 8, No. 4, 2019, E-ISSN: 2226-6348 @ 2019 HRMARS

\section{References}

Ahern, L., Feller, J., \& Nagle, T. (2016). Social media as a support for learning in universities : an empirical study of Facebook Groups. Journal of Decision Systems, 25, 35-49. https://doi.org/10.1080/12460125.2016.1187421

Annamalai, N., \& Jaganathan, P. (2017). Reflective practice paper, 25(2), 3-17.

Ayan, D., \& Seferoglu, G. (2011). Using electronic portfolios to promote reflective thinking in language teacher education. Educational Studies, 37(5), 513-521.

https://doi.org/10.1080/03055698.2010.539782

Bicen, H., \& Cavus, N. (2011). Social network sites usage habits of undergraduate students : case study of Facebook. Procedia - Social and Behavioral Sciences, 28, 943-947. https://doi.org/10.1016/j.sbspro.2011.11.174

Bosch, T. E. (2009). Using online social networking for teaching and learning : Facebook use at the University of Cape, 0167(January). https://doi.org/10.1080/02500160903250648

Bruster, B. G., \& Peterson, B. R. (2013). Reflective Practice : International and Multidisciplinary Perspectives Using critical incidents in teaching to promote reflective practice, (May 2015), 37-41. https://doi.org/10.1080/14623943.2012.732945

Cimer, S. O. (2011). The effect of portfolios on students' learning: student teachers' views. European Journal of Teacher Education, 34(2), 161-176. https://doi.org/10.1080/02619768.2011.552183

Coulson, D. H. M., Coulson, D., \& Harvey, M. (2013). Scaffolding student reflection for experiencebased learning: a framework. Teaching in Higher Education, 18(4), 401-413. https://doi.org/10.1080/13562517.2012.752726

Department Of Statistics, M. (2016). Press Release ICT Use And Access By Individuals And Households Survey Report, .

Donlan, L. (2012). Exploring the views of students on the use of Facebook in university teaching and learning. Journal of Further and Higher Education, (November), 1-17. https://doi.org/10.1080/0309877X.2012.726973

Grosseck, G., Bran, R., \& Tiru, L. (2011). Dear teacher, what should I write on my wall ? A case study on academic uses of Facebook. Procedia - Social and Behavioral Sciences, 15, 14251430. https://doi.org/10.1016/j.sbspro.2011.03.306

Hew, K. F. (2011). Students' and teachers' use of Facebook. Computers in Human Behavior, 27(2), 662-676. https://doi.org/10.1016/j.chb.2010.11.020

Hussain, I. (2012). A Study to Evaluate the Social Media Trends among University Students, 64, 639-645. https://doi.org/10.1016/j.sbspro.2012.11.075

Jamil, H., Razak, N. A., Raju, R., \& Mohamed, A. R. (2010). Teacher Professional Development: Issues and Challenges., 200, 85-102.

Jones, M., \& Ryan, J. (2014). Asia-Pacific Journal of Teacher Learning in the practicum : engaging pre-service teachers in reflective practice in the online space, (May 2015), 37-41. https://doi.org/10.1080/1359866X.2014.892058

Kabilan, M. K. (2008). Challenges Faced and the Strategies Adopted by a Malaysian English Language Teacher during Teaching Practice, (2002), 87-95.

Killeavy, M., \& Moloney, A. (2010). Reflection in a social space: Can blogging support reflective practice for beginning teachers? Teaching and Teacher Education, 26(4), 1070-1076. 
INTERNATIONAL JOURNAL OF ACADEMIC RESEARCH IN PROGRESSIVE EDUCATION AND

DEVELOPMENT

Vol. 8, No. 4, 2019, E-ISSN: 2226-6348 @ 2019 HRMARS

https://doi.org/10.1016/j.tate.2009.11.002

Kori, K., Pedaste, M., Leijen, A., \& Maeots, M. (2014). Supporting reflection in technologyenhanced learning. Educational Research Review, 11, 45-55.

https://doi.org/10.1016/j.edurev.2013.11.003

Kumar, S., Joshi, A., \& Sharma, H. (2016). Computers in Human Behavior A multi-analytical approach to predict the Facebook usage in higher education. Computers in Human Behavior, 55, 340-353. https://doi.org/10.1016/j.chb.2015.09.020

Kurtz, G. (2014). Integrating a Facebook Group and a Course Website : The Effect on Participation and Perceptions on Learning Integrating a Facebook Group and a Course Website: The Effect on Participation and Perceptions on Learning, 3647(May).

https://doi.org/10.1080/08923647.2014.957952

Lee, B. I. (2008). Fostering Preservice Reflection through Response Journals, 117-139.

Madge, C., Meek, J., Wellens, J., Hooley, T., Madge, C., Meek, J., ... Facebook, T. H. (2009). Facebook, social integration and informal learning at university : 'It is more for socialising and talking to friends about work than for actually doing work ', 9884(May). https://doi.org/10.1080/17439880902923606

Malaysian Communication and Multimedia Commission. (2018). Internet User Survey 2018 : Statistical Brief Numbered Twenty-Three. Internet Users Survey 2018, (ISSN 1823-2523), 139. Retrieved from https://www.mcmc.gov.my/skmmgovmy/media/General/pdf/InternetUsers-Survey-2018.pdf

Manca, S., \& Ranieri, M. (2016). "yes for sharing, no for teaching!": Social Media in academic practices. Internet and Higher Education, 29, 63-74.

https://doi.org/10.1016/j.iheduc.2015.12.004

Mansor, A. Z. (2011). Reflective Learning Journal Using Blog, 18, 507-516.

https://doi.org/10.1016/j.sbspro.2011.05.074

Masry, T. Em., \& Saad, M. R. B. M. (2017). Complexities and Tensions ESL Malaysian Student Teachers Face during their Field Practice. The English Teacher, 46(1), 1-16.

Mutlu, G. (2014). Challenges in Practicum: Pre-Service and Cooperating Teachers' Voices. Journal of Education and Practice, 5(36), 1-7.

Petrovic, N., Jeremic, V., Cirovic, M., Radojicic, Z., Petrovic, N., Jeremic, V., ... Radojicic, Z. (2016). Facebook Versus Moodle in Practice Facebook Versus Moodle in Practice, 3647(May). https://doi.org/10.1080/08923647.2014.896581

Pimmer, C., \& Linxen, S. (2012). social network sites from mobile phones in developing countries . https://doi.org/10.1111/j.1467-8535.2012.01351.x/abstract

Prescott, J., Stodart, M., Becket, G., Wilson, S., Prescott, J., Stodart, M., ... Wilson, S. (2015). Educational Tool The Experience of using Facebook as an Educational Tool, 0888. https://doi.org/10.11120/hsce.2013.00033

Rasiah, R. R. V. (2014). Transformative Higher Education Teaching and Learning: Using Social Media in a Team-Based Learning Environment. Procedia - Social and Behavioral Sciences, 123(2012), 369-379. https://doi.org/10.1016/j.sbspro.2014.01.1435

Sánchez, R. A., Cortijo, V., \& Javed, U. (2014). Computers \& Education Students ' perceptions of Facebook for academic purposes. Computers \& Education, 70, 138-149. https://doi.org/10.1016/j.compedu.2013.08.012 
Schon, D. (1983). The Reflective Practitioner: How Professionals Think in Action. New York: NY: Basic Books.

Selwyn, N. (2009). Faceworking : exploring students ' education-related use of Facebook, 34(2), 157-174. https://doi.org/10.1080/17439880902923622

Sendurur, P., Sendurur, E., \& Yilmaz, R. (2015). Computers in Human Behavior Examination of the social network sites usage patterns of pre-service teachers. Computers in Human Behavior, 51, 188-194. https://doi.org/10.1016/j.chb.2015.04.052

Sharar, T. (2012). Introducing reflective practice to teachers in an English medium lower secondary private school in Chitral, 2(May), 277-284.

Stuart, S., \& Weber, S. (2013). CAN PRESERVICE TEACHERS BE TAUGHT TO BECOME REFLECTIVE THINKERS DURING THEIR FIRST INTERNSHIP EXPERIENCE ? by A Dissertation Presented in Partial Fulfillment of the Requirements for the Degree Doctor of Education Liberty University.

Tang, E., \& Lam, C. (2014). Building an effective online learning community (OLC) in blog-based teaching portfolios. Internet and Higher Education, 20, 79-85. https://doi.org/10.1016/j.iheduc.2012.12.002

Villiers, M. R. R. D. (2010). Academic Use of a Group on Facebook : Initial Findings and Perceptions Literature Study General Use by University Students. Informing Science. https://doi.org/10.28945/1242

Wang, Q., Woo, H. L., Quek, C. L., Yang, Y., \& Liu, M. (2012). Using the Facebook group as a learning management system: An exploratory study. British Journal of Educational Technology (Vol. 43). https://doi.org/10.1111/j.1467-8535.2011.01195.x

Wilson, R. E., Gosling, S. D., \& Graham, L. T. (2012). A Review of Facebook Research in the Social Sciences. Perspectives on Psychological Science (Vol. 7). https://doi.org/10.1177/1745691612442904

Yunus, M. M., Hashim, H., Ishak, N. M., \& Mahamod, Z. (2010). Understanding TESL pre-service teacher's teaching experiences and challenges via post-practicum reflection forms. Procedia - Social and Behavioral Sciences, 9, 722-728. https://doi.org/10.1016/j.sbspro.2010.12.224 